\title{
Influence of Normal Force and Tangential Braking Force on the Fatigue Damage
}

\author{
Wen Zhong, Wei Qin, Guo Jun \& Qiyue Liu \\ Southwest Jiaotong University, Chengdu 610031, China \\ E-mail: zw1019@126.com
}

The research is financed by the National High Technology Research and Development Program of China (863 Program) (No. 2009AA04Z424), The National Basic Research Program of China (973 Program) (No. 2007CB714702), The National Natural Science Foundation of China (No. 50675183) and the Innovation Team Cultivation Plan of Southwest Jiaotong University (No. 2007IRT01). (Sponsoring information)

\begin{abstract}
The rolling tests of railway rail were performed using a JD-1 wheel/rail simulation facility without any lubricant. The failure behavior of rail rollers with different materials was investigated in detail by examining wear volume and wear scar using optical microscopy (OM) and scanning electronic microscopy (SEM). The results indicate that with the increase of the normal forc and Tangential Braking Force e, the wear of rail increases, and the rail presents obvious plastic flow.
\end{abstract}

Keywords: Rail, Normal force, Fatigue crack, Crack spread angle, Plastic flow

The railway transportation can effectively reduce the transportation cost and enhance the transportation efficiency and labor productivity, and it is the main technical measure to enhance the transportation capacity of heavy bulk cargos, and it is also the development direction of future railway freight. Daqin Line west starts from Shanxi Datong junction Hanjialing, and east arrives at Hebei Qinhuangdao, and the span of the line is $653 \mathrm{~km}$, and it was the first special heavy haul coal freight line giving priority to heavy loading unit and combined trains in China, and its freight had achieved 31.5 billion tons in 2008 (Liu, 2004, P.82-87). With the development of the highway and heavy haul railway, many urgent problems begin to occur in the railway transportation, such as the contact fatigue and abrasion of wheel-rail rolling, and these basic problems have seriously limited the development of the railway transportation. The invalidation of rail will impact the normal operation of trains, and be the hidden trouble of the safe railway transportation, even induce significant railway accident (H.D. Grohmann, 2002, P.67-74).

The rail damage mainly includes the attrition loss, the corrugation loss, the contact fatigue, the side abrasion and stripping (Kapoor A, 2002, P.25-28). When the contract stress of rail exceeds the rail yield stress, the plastic distortion will occur on the surface of the contact metal, and the fatigue crack generates on the surface and extends along the distortion direction (Clayton P, 1980, P.75-93). When the rail abrasion speed is smaller than the fatigue extension speed, the stripping will occur. In this article, by the simulated test, the influence of the normal force and the tangential braking force on the rolling contact fatigue performance of rail material will be researched as follows.

\section{Abrasion test}

The JD-1 wheel-rail stimulated tester (seen in Figure 1) is adopted in the test (Liu, 2003, P.132-135). To ensure the similarity of the fraction process in the test condition and the locale situation, according to the Hertz Contact Theory, the average contact stress among the simulated wheel-rail samples in the test condition and the ratio of long and short semi-axes of the contact ellipse should be same to the locale situation. The truckle sample is taken from the railhead, and the end face of the ample is parallel with the tread of rail, and the diameter of truckle is 62 $\mathrm{mm}$, and the diameter of bull wheel is $1153 \mathrm{~mm}$. The chemical components and content of the wheel and rail are seen in Table 1, and the relative mechanical performances are seen in Table 2, and the simulation times of the bull wheel circulation is $10^{6}$, and all rolling tests are operated in the dry condition. The optical microscope is utilized in the test to observe the plastic flow of rail, and the X650 scanning electron microscope is used to observe the edge appearance of the junction of the section and the abrasion surface.

\section{Analysis of abrasion loss}

The abrasions of the rail samples in different normal forces are seen in Figure 2. When other conditions are same, with the increase of normal force, the abrasion loss gradually increases, and the abrasion loss is minimum loss 
when the normal force is $16 \mathrm{t}$. In the same normal force, when the tangential braking force exists, the abrasion loss of rail far exceeds the abrasion loss of rail without the tangential braking force. It is obvious that the tangential braking force will significantly impact the abrasion of rail.

\section{Analysis of surface abrasion scratch}

The surface appearances of rail sample in different normal forces are seen in Figure 3. Figure 3 (a) is the abrasion when the tangential braking force exists and the tangential normal force is $16 \mathrm{t}$, and Figure 3 (b) is the abrasion when the tangential braking force exists and the tangential normal force is 25 t, and Figure 3 (b) is the abrasion when the tangential braking force doesn't exist and the tangential normal force is 16t, and Figure 3 (d) is the abrasion when the tangential braking force doesn't exist and the tangential normal force is $25 \mathrm{t}$.

From Figure 3 (a) and Figure 3 (b), when other conditions are same, with the increase of normal force, the abrasion of rail surface becomes deeper, and more cracks occur, which indicates that the rail has serious fatigue damage. In Figure 3 (c) and Figure 3 (d), without the tangential braking force, same phenomena occur.

Comparing Figure 3 (a) with Figure 3 (c), the abrasion of the sample in Figure 3 (a) is obviously more and deeper than the sample in Figure 3 (c), and the stripping also occurs. Same phenomena occur in Figure (2) and Figure (4), which indicates that the braking force will significantly increase the abrasion of wheel to the rail.

\section{Micro appearance}

The mutual function of wheel-rail contact will induce the plastic area of the sample abrasion face, and finally from the plastic flow and the fatigue crakes (Liu, 2003, P.56-59 \& Zhong, 2008, P.1740-1743 \& Zhao, 2007, P.100-102), and the depth and the fatigue cracks of the flow layer will be the indexes to show the damage degree of the surface of materials.

To analyze the plastic distortion of sample, the sample is cut along the vertical rolling direction, and the organization appearance of the section could be observed. Figure 4 is the micro appearance of the rail sample section along the vertical rolling direction. From Figure 4, when the normal force is 16 t, the plastic flow layer of the rail becomes thinner and even (seen in Figure 4 (a)), and when the normal force is 25 t, the plastic flow layer of the rail becomes deeper and uneven. In addition, in same normal force, without the tangential braking force, the contact area flow layer of the flange and the railhead becomes thinner, and the plastic flow induces. On the contrary, with the tangential braking force, the plastic flow of sample is obvious.

\section{Conclusions}

(1) With the increase of normal force, the abrasion loss of rail will increase and the plastic flow layer becomes deeper.

(2) In the same working condition of normal force, the influence of the tangential braking force on the rail abrasion and plastic flow is significant.

\section{References}

Clayton P. (1980). The relationship between wear behaviors and basic material properties for pearltic steel. Wear, No.60(2). P. 75-93.

H.D. Grohmann, Klaus H, Arnold G T. (2002). A new type of RCF, experimental investigations and theoretical modeling. Wear, No. 2539(1). P. 67-74.

Kapoor A, Schmid F, Fletcher D I. (2002). Managing the critical wheel/rail interface. Railway Gazette International, No.158 (1). P. 25-28.

Liu, Qiyue, Zhang, Bo, Zhou, Zongrong, et al. (2003). Experimental study on rolling wheel corrugation. Tribology, No. 23(2). P. 132-135.

Liu, Tianmo, Zhou, Shouze, Zuo, Rulin, et al. (2003). Effect of vanadium on pearlite in PD3 steel. Iron and steel, No. 38(4). P. 56-59.

Liu, Xuewen, Zou, Dingqiang, Xing, Lixian, et al. (2004). Causes of rail tread oblique crack and countermeasures. China Railway Science, No. 25(2). P. 82-87.

Zhao, Xueqin, Zhong, Wen, Wang, Wenjian, et al. (2007). Analysis of rail damage behavior of high-speed and heavy-haul railway. Lubrication Engineering, No. 32(10). P. 100-102.

Zhong, Wen, Zhao Xueqin, Wang, Wenjian, et al. (2008). A study on growth behavior of fatigue crack of PD3 and U71Mn rail. China Mechanical Engineering, No. 19(14). P. 1740-1743. 
Table 1. Chemical components of rail material

\begin{tabular}{|c|c|c|c|c|c|c|}
\hline & wC & wSi & wMn & wP & wS & wV \\
\hline Rail & 0.796 & 0.566 & 0.700 & $\leq 0.030$ & $\leq 0.03$ & 0.120 \\
\hline Wheel & 0.625 & 0.371 & 1.350 & $\leq 0.030$ & $\leq 0.05$ & 0.040 \\
\hline
\end{tabular}

Table 2. Mechanical performance of rail material

\begin{tabular}{|c|c|c|c|}
\hline & $\sigma \mathrm{b}(\mathrm{MPa})$ & $\psi(\%)$ & HV0.2 \\
\hline Rail & $\geq 1200$ & $\geq 14$ & $\geq 359$ \\
\hline Wheel & $\geq 800$ & $\geq 14$ & $\geq 241$ \\
\hline
\end{tabular}

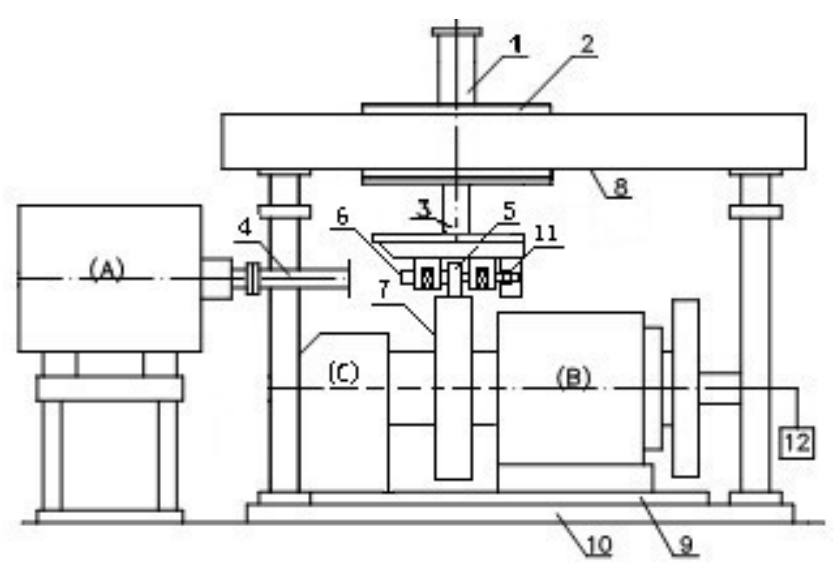

Figure 1. Sketch Map of JD-1 Wheel-rail Fraction Tester

Note: A, B: ZQDR-204 DC Electromotor, C: Gear-box, 1: Vertical Loading Cylinder, 2: Loading Dolly, 3: Mandrel and Yoke Support, 4: Cardan Shaft, 5: Simulated Truckle Sample, 6: Simulated Sample Dabber, 7: Simulated Bull Wheel, 8: Suspension Beam of Cylinder, 9: Turntable, 10: Base Table, 11: Braking Force Piezoelectric Transducer, 12: Speed Measuring Motor.

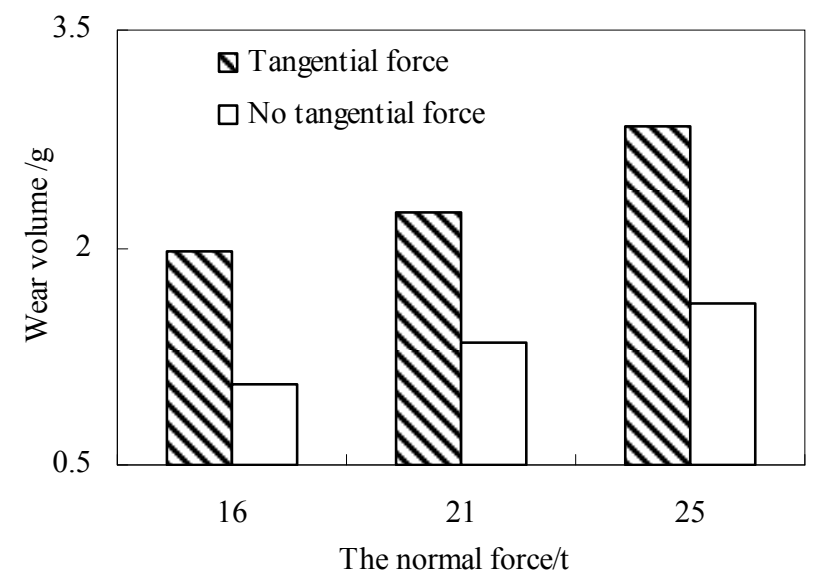

Figure 2. Comparison of Rail Abrasion Losses in Different Normal Forces 


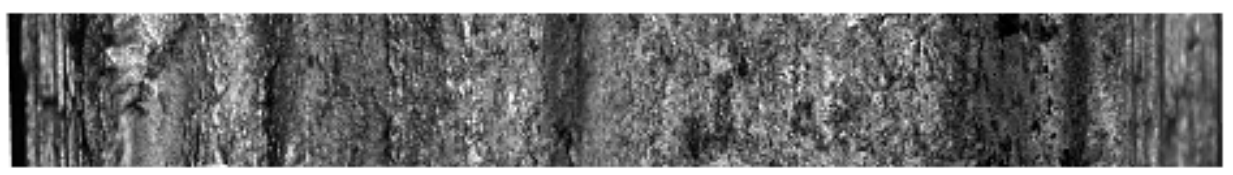

(a)

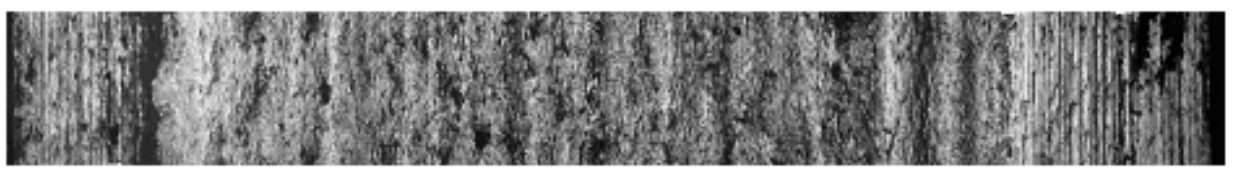

(b)

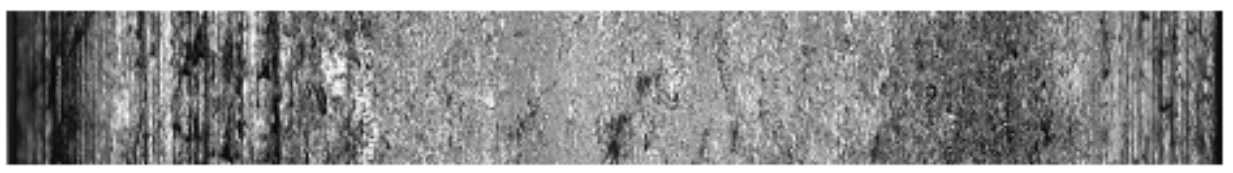

(c)

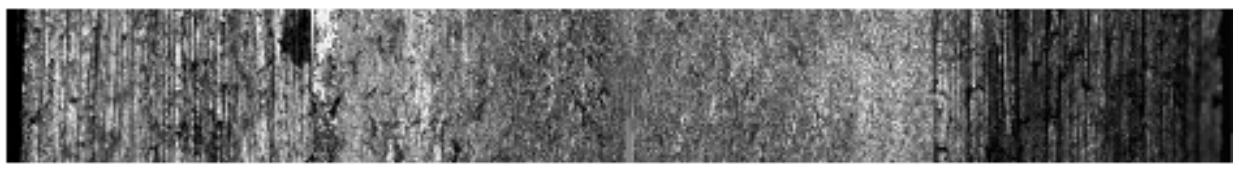

(d)

Figure 3. Analysis of Surface Appearances of Rail in Different Normal Forces

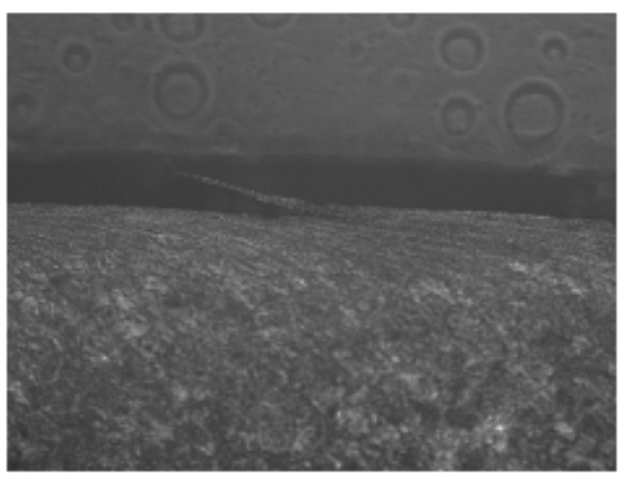

(a)

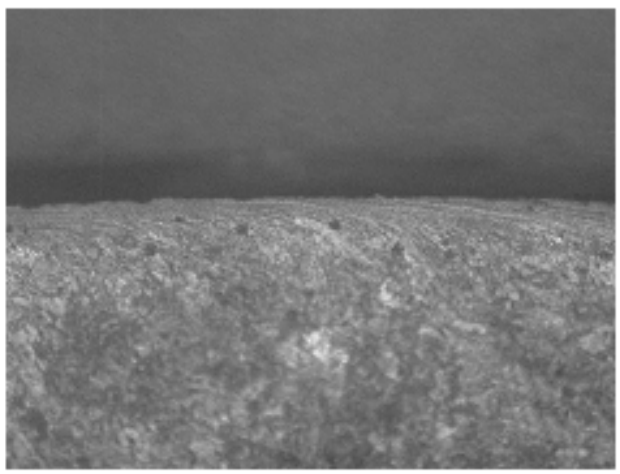

(c)

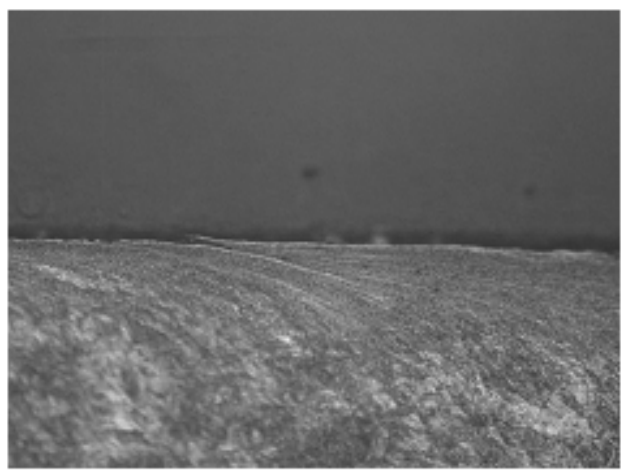

(b)

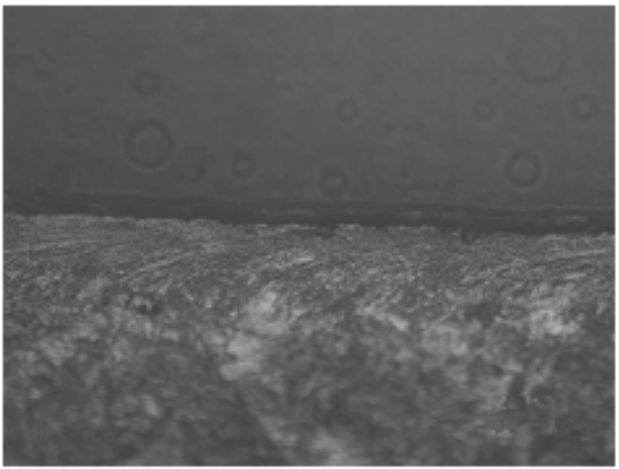

(d)

Figure 4. Plastic Flow of Rail Sample 